\title{
Editorial \\ Numerical Modelling in Steel Metallurgy
}

\author{
Markéta Tkadlečková
}

Citation: Tkadlečková, $\mathrm{M}$.

Numerical Modelling in Steel

Metallurgy. Metals 2021, 11, 885.

https: / / doi.org/10.3390/

met11060885

Received: 26 May 2021

Accepted: 27 May 2021

Published: 28 May 2021

Publisher's Note: MDPI stays neutral with regard to jurisdictional claims in published maps and institutional affiliations.

Copyright: (C) 2021 by the author. Licensee MDPI, Basel, Switzerland.

This article is an open access article distributed under the terms and conditions of the Creative Commons Attribution (CC BY) license (https:// creativecommons.org/licenses/by/ $4.0 /)$.
Faculty of Materials Science and Technology, VŠB-Technical University of Ostrava, 17 Listopadu 2172/15, 70800 Ostrava, Czech Republic; marketa.tkadleckova@vsb.cz

\section{Introduction and Scope}

Steel production represents a complex process which is accompanied by a series of physical-chemical processes from melting, through the multiphase flow of steel and chemical reactions (processes taking place between the slag, metal, and an inert gas) after solidification. A frequent problem in steel production is setting the correct conditions of these processes., e.g., the vacuum degassing of steel, optimising the nature of flow in individual reactors (tundish, moulds), or the conditions for casting and the solidification of steel. Understanding these mechanisms requires knowledge of the technology of steel production, metallurgical thermodynamics, and kinetics. The other two mutually dependent requirements, which help to understand the production of steel, are experimental measurements and the modelling of processes. Especially in demanding metallurgical conditions, where it is very difficult to obtain information about the steel flows in metallurgical plants, or about the solidification point and the macrostructure of solidified metal, the method of numerical modelling plays an irreplaceable role. This Special Issue presents new knowledge and trends in the optimisation of steel production using numerical modelling.

\section{Contributions}

Twelve research articles about numerical modelling in steel metallurgy have been published in this Special Issue. The contributions cover the whole spectrum of the production steps of steel, where numerical modelling for the optimisation of steel processes was used.

The questions related to the preparation of primary charge are published in [1], where $\mathrm{Li}$ et al. describe the numerical modelling of the $\mathrm{FeO}$ reduction process in a rotary hearth furnace and analyse the effects of the gas field and the bottom of the furnace on the direct reduction of multilayer ellipsoidal pellets. The local environmental viewing angle coefficient in the model is obtained. Furthermore, the porosity variation in the pellet during the direct reduction process is also considered.

As the consumption of steel scrap during primary metallurgy is still growing, the second contribution of Deng et al. [2] is devoted to the investigation of scrap melting in hot metal with a high carbon content under different melting temperatures by carrying out experiments and numerical models. The experiments demonstrate that steel can be melted under its melting point when the bar is immersed in hot metal which contains a high concentration of carbon. The study also shows the temperature distributions of the bath and the effects of temperature on the melting behaviours during the melting process. Additionally, the effects of carbon content in the bar and bath metal are considered.

After primary metallurgy of steel, the methods of secondary metallurgy play a crucial role which affects the final quality of steel. In view of the serious splashing problem in the 120-ton Ruhrstahl Heraeus (RH) refining process of a special steel company, a coupling model of volume of fluid with a discrete phase model is established by Zhao et al. [3] to study the influence of the vacuum pressure drop mode on the RH vacuum splashing. The model predicts that the most serious splashing situation of liquid drops would happen at the early stage of vacuum treatment, which is consistent with the results found in industrial production. 
Four contributions related to the numerical simulation of steel flow in tundish of a continuous casting machine start with Tkadlečková et al. [4], who provide a numerical analysis of RTD curves and inclusion removal in a multi-strand asymmetric tundish with different configurations of impact pads. The complex procedure of numerical modelling in the programme ANSYS Fluent is described. The papers of Sheng et al. [5-7] describe a computational fluid dynamic (CFD) modelling study for analysing the flow pattern and the residence time distribution in a five-strand tundish. The numerical modelling results are compared to water-modelling results to validate the mathematical model. The volume fraction of different flow regions (plug, mixed, and dead) and the intermixing time during the ladle changeover are calculated to study the effects of the flow control device (FCD) on the tundish performance. Additionally, a mathematical model is developed to study the effects of the flow control devices and the gas curtain on the steel's cleanliness in a singlestrand tundish. The results show that the flow control devices and the gas curtain reduce the extent of the dead volumes in the tundish and thus enhance the removal efficiency of the inclusions. For a single-strand tundish, a novel digital design methodology that combines computational fluid dynamics (CFD) modelling and the Taguchi-Grey relational analysis method is also presented.

The final quality of steel can also be affected by the conditions of casting and solidification. Therefore, much attention is also devoted to numerical modelling of processes during the continuous casting of steel. The contribution of Wang et al. [8] presents the investigation of surface velocity in a $150 \mathrm{~mm} \times 1270 \mathrm{~mm}$ slab continuous-casting mould. Taking the slag layer into consideration, a numerical simulation was performed which was validated by a particle image velocimetry test. The results show that the maximum surface velocity was $0.739 \mathrm{~m} / \mathrm{s}$ around the mid-section of the free surface, and the results of nail-board experiments are more accurate when the steel nail diameter was $10 \mathrm{~mm}$. A segmented coupling model for slab casting by roller electromagnetic stirring (R-EMS) of electromagnetic, flow, heat transfer, and solidification behaviour based on magnetohydrodynamics and solidification theory is presented by Xiao et al. in [9]. The accuracy of the model is verified by measuring the magnetic flux density at the centreline in a pair of rollers and the electromagnetic force of the copper plate. When increasing the number of pairs of rollers, the effective stirring region increased, and the velocity of molten steel at the solidification front first increased but then decreased. To investigate the deformation behavior of $\varnothing 195 \mathrm{~mm}$ round continuously cast steel bloom during soft reduction (SR) in the reduction force mode, a two-dimensional thermal-mechanical coupled model was developed by Li et al. in [10]. According to the simulation results, a multi-unit soft reduction plan is proposed. After the reduction process, the shrinkage porosity in the centre of the round bloom almost vanished, while the number and size of spot segregations were significantly reduced. Moreover, the oil pipe produced by the round bloom with SR had a better resistance to sulfide stress corrosion.

The Special Issue is concluded by articles about the optimisation of the casting and forming of steel ingots. Odehnal et al. [11] deal with numerical modelling for developing a mould geometry suitable for casting both low- and high-alloy steel grades into $500 \mathrm{~kg}$ experimental ingots [11]. Finally, Jonšta et al. [12] describe numerical modelling and an operational experiment applied to optimise the forging of a P40N slab ingot from $55 \mathrm{NiCrMoV7}$ tool steel. The results indicate that in selected cases, the use of a P40N slab ingot instead of the conventional polygonal $8 \mathrm{~K}$ forging ingot can be considered in the production of certain plate-type forgings.

\section{Conclusions and Outlook}

The published papers provide a comprehensive insight into current research in the field of the utilisation of numerical modelling for the verification and optimisation of processes during the production and casting of steel. Readers have the opportunity to see the significant applicability of numerical modelling. The contributions show the settings of numerical models and the results can be transferred to real practice conditions. This Special Issue is also the 
platform for the next SI, Numerical Modelling in Steel Metallurgy: https:/ /www.mdpi.com/ journal/metals/special_issues/numerical_modelling_2021 (accessed on 28 May 2021).

Funding: This work was financially supported by the project No. CZ.02.1.01/0.0/0.0/17_049/0008399 from the EU and CR financial funds provided by the Operational Programme Research, Development and Education, Call 02_17_049 Long-Term Intersectoral Cooperation for ITI, Managing Authority: Czech Republic-Ministry of Education, Youth and Sports.

Conflicts of Interest: The authors declare no conflict of interest.

\section{References}

1. Li, N.; Wang, F. Numerical analysis of radiative heat transfer and direct reduction of three-dimensional multilayer ellipsoidal carbon-containing pellet unit in the rotary hearth furnace. Metals 2020, 10, 994. [CrossRef]

2. Deng, N.; Zhou, X.; Zhou, M.; Peng, S. Numerical simulation of the melting behavior of steel scrap in hot metal. Metals 2020, 10, 678. [CrossRef]

3. Zhao, Z.-J.; Wang, M.; Song, L.; Bao, Y.-P. Splashing simulation of liquid steel drops during the ruhrstahl heraeus vacuum process. Metals 2020, 10, 1070. [CrossRef]

4. Tkadlečková, M.; Walek, J.; Michalek, K.; Huczala, T. Numerical analysis of RTD curves and inclusions removal in a multi-strand asymmetric tundish with different configuration of impact pad. Metals 2020, 10, 849. [CrossRef]

5. Sheng, D.-Y.; Yue, Q. Modeling of fluid flow and residence-time distribution in a five-strand tundish. Metals 2020, $10,1084$. [CrossRef]

6. Sheng, D.-Y. Mathematical modelling of multiphase flow and inclusion behavior in a single-strand tundish. Metals 2020, 10, 1213. [CrossRef]

7. Sheng, D.-Y. Design optimization of a single-strand tundish based on CFD-taguchi-grey relational analysis combined method. Metals 2020, 10, 1539. [CrossRef]

8. Wang, Y.; Feng, J.; Yang, S.; Li, J. Measurement of surface velocity in a $150 \mathrm{~mm} \times 1270 \mathrm{~mm}$ Slab continuous-casting mold. Metals 2020, 10, 428. [CrossRef]

9. Xiao, H.; Wang, P.; Yi, B.; Chen, X.; Li, A.; Tang, H.; Li, W.; Zhang, J. A Numerical and experimental study on the solidification structure of $\mathrm{Fe}-\mathrm{Cr}-\mathrm{Ni}$ steel slab casting by roller electromagnetic stirring. Metals 2021, 11, 6. [CrossRef]

10. Li, L.; Zhang, Z.; Luo, M.; Li, B.; Lan, P.; Zhang, J. Control of shrinkage porosity and spot segregation in Ø195 mm continuously cast round bloom of oil pipe steel by soft reduction. Metals 2021, 11, 9. [CrossRef]

11. Odehnal, J.; Ludvík, P.; Studecký, T.; Michálek, P. Development of universal mould geometry for the teeming of cylindrical iron-base alloy ingots. Metals 2021, 11, 471. [CrossRef]

12. Jonšta, P.; Kurka, V.; Vindyš, M.; Kander, L. The effect of forging conditions on final macrostructure of Slab ingot from the 55NiCrMoV7 tool steel. Metals 2021, 11, 435. [CrossRef] 